\title{
Promoter de-methylation of cyclin D2 by sulforaphane in prostate cancer cells
}

\author{
Anna Hsu ${ }^{1,2}$, Carmen P Wong ${ }^{1,2}$, Zhen Yu ${ }^{3}$, David E Williams ${ }^{2,3}$, Roderick H Dashwood ${ }^{2,3}$ and Emily Ho 1,2* $^{*}$
}

\begin{abstract}
Sulforaphane (SFN), an isothiocyanate derived from cruciferous vegetables, induces potent anti-proliferative effects in prostate cancer cells. One mechanism that may contribute to the anti-proliferative effects of SFN is the modulation of epigenetic marks, such as inhibition of histone deacetylase (HDAC) enzymes. However, the effects of SFN on other common epigenetic marks such as DNA methylation are understudied. Promoter hyper-methylation of cyclin D2, a major regulator of cell cycle, is correlated with prostate cancer progression, and restoration of cyclin D2 expression exerts anti-proliferative effects on LnCap prostate cancer cells. Our study aimed to investigate the effects of SFN on DNA methylation status of cyclin D2 promoter, and how alteration in promoter methylation impacts cyclin D2 gene expression in LnCap cells. We found that SFN significantly decreased the expression of DNA methyltransferases (DNMTs), especially DNMT1 and DNMT3b. Furthermore, SFN significantly decreased methylation in cyclin D2 promoter regions containing c-Myc and multiple Sp1 binding sites. Reduced methlyation of cyclin D2 promoter corresponded to an increase in cyclin D2 transcript levels, suggesting that SFN may de-repress methylation-silenced cyclin D2 by impacting epigenetic pathways. Our results demonstrated the ability of SFN to epigenetically modulate cyclin D2 expression, and provide novel insights into the mechanisms by which SFN may regulate gene expression as a prostate cancer chemopreventive agent.
\end{abstract}

Keywords: Sulforaphane, methylation, prostate cancer, cyclins, chemo-prevention

\section{Introduction}

Studies have shown that high consumption of cruciferous vegetables is inversely associated with prostate cancer risk [1-5]. Cruciferous vegetables and their biologically active constituents, including isothiocyanates (ITCs) such as sulforaphane (SFN), appear to modulate prostate cancer risk at multiple stages of carcinogenesis. SFN is an effective chemoprotective agent for prostate cancer in both in vitro and in vivo models by selectively inducing apoptosis and slowing tumor growth [6-10]. More recently, SFN has been shown to induce anti-proliferative effects via epigenetics, namely acting as a dietary histone deacetylase (HDAC) inhibitor. SFN treatment leads to an increase in histone acetylation and re-expression of various tumor suppressor genes [11-13]. SFN-mediated epigenetic alterations may not only be limited to HDAC regulation. Studies suggest

\footnotetext{
* Correspondence: emily.ho@oregonstate.edu

'School of Biological and Population Health Sciences, 103 Milam Hall,

Oregon State University, Corvallis, OR 97331, USA Full list of author information is available at the end of the article
}

that SFN may play an important role in methyl CpGbinding proteins' recruitment of HDAC family members [14]. In breast cancer cells, SFN suppresses DNA methylation in the $h T E R T$ promoter, leading to transcriptional repression [15]. Together, these data suggest that there may be multiple mechanisms by which SFN epigenetically regulates gene expressions.

Cell cycle progression is controlled by cyclin-dependent kinases (CDKs) and their activities are further regulated by cyclins and $\mathrm{CDK}$ inhibitors. D-type cyclins (D1, D2, and D3) are mainly implicated in G1 to S phase transition [16]. Dys-regulation of the cyclin Ds disrupts cell cycle control and promotes neoplastic transformation. Cyclin D2/CCND2 has been identified in several cancers as a proto-oncogene. Over-expression of cyclin D2 correlates with progression and poor prognosis in gastric cancer $[17,18]$, colon cancer [19] and granulosa cell tumors of the ovary [20]. However, silencing of cyclin D2 expression by promoter methylation is also associated with cancer progression in breast cancer [21-23], lung [23], pancreatic [24] and gastric cancer
Ciomed Central 
[25], suggesting that cyclin D2 might act as a tumor suppressor gene in a cancer-type dependent manner. In prostate cancer, increased cyclin D2 promoter methylation corresponds to a decrease in cyclin D2 mRNA expression, and correlates with higher Gleason scores and pathologic features of tumor aggressiveness [26]. The present study was undertaken to evaluate the effects of SFN on the epigenetic regulation of cyclin D2 in prostate cancer cells. Our results indicate that SFN may down-regulate DNA methyltransferases (DNMTs) resulting in de-methylation of the cyclin $D 2$ promoter and de-repression of cyclin D2 expression, and suggest a novel mechanism behind SFN's growth inhibitory effects on prostate cancer cells.

\section{Materials and methods}

\section{Cell Culture and Treatment}

Benign prostate hyperplasia (BPH-1) cells were generously donated by Dr. Simon Hayward (Vanderbilt University Medical Center, Nashville, TN); androgen dependent prostate cancer epithelial cells (LnCap) and androgen-independent prostate cancer epithelial cells (PC3) were obtained from America Type Culture Collection (Manassas, VA). Cells were grown and maintained in RPMI 1640 supplemented with glutamine (Mediatech Inc., Manassas, VA), 1\% penicillin-streptomycin (Mediatech Inc., Manassas, VA) and 10\% (5\% for BPH-1 cells) fetal bovine serum (FBS) (Hyclone, Logan, $\mathrm{UT})$ under standard conditions $\left(5 \% \mathrm{CO}_{2}, 37^{\circ} \mathrm{C}\right.$, humidified atmosphere). R, S-Sulforaphane (SFN, LKT Laboratories, Inc., St. Paul, MN) was dissolved in dimethyl sulfoxide (DMSO) or ethanol (EtOH) (Sigma-Aldrich). Vehicle treatments consisted of DMSO or EtOH in a final concentration matching the highest level of treated cells $(30 \mu \mathrm{M}$ SFN) and was less than $0.1 \%$ of the final volume. Cells were treated with vehicle or SFN (15 or $30 \mu \mathrm{M}$ ) for 24 or 48 hours.

\section{mRNA expression levels of DNMTs by quantitative real- time PCR (qRT-PCR)}

Total RNA was extracted using TRIzol Reagent (Invitrogen, Carlsbad, CA) according to the manufacturer's instructions. Total RNA (1 $\mu \mathrm{g})$ was reverse-transcribed into cDNA using SuperScript III First-Strand Synthesis Supermix (Invitrogen, Carlsbad, CA) containing reaction buffer, $\mathrm{MgCl}_{2}$, dNTPs and a 1:1 mixture of random hexamers and oligo-dT primers. For qRT-PCR, the primer sequences were as follows: DNMT1, (sense) 5'GTG GGGGACTGTGTCTCTGT-3' and (antisense) 5'TGAAAGCTGCATGTCCTCAC-3'; DNMT3a, (sense) 5'-CACACAGAAGCATATCCAGGAGTG-3' and (antisense) 5'-AGTGGACTGGGAAACCAAATACCC-3'; DNMT3b, (sense) 5'-AATGTGAATCCAGCCAGGAAAGGC-3' and (antisense) 5'-ACTGGATTAC
ACTCCAGGAACCGT-3'; CCND2, (sense) 5'TGGAGCTGCTGTGCCACG -3' and (antisense) 5'GTGGCCACCATTCTGCGC-3' and GAPDH (sense) 5'CGAGATCCCTCCAAAATCAA- 3' and (antisense) 5'TTCACACCCATGACGAACAT-3'. The reactions were performed using DyNAmo HS SYBRGreen qPCR kit (New England Biolabs, Ipswich, MA) on a Chromo4 Thermal Cycler (MJ Research, Inc., Waltham, MA). PCR conditions were programmed as follows: $95^{\circ} \mathrm{C}$ for $5 \mathrm{~min}$, followed by 40 cycles of denaturing at $95^{\circ} \mathrm{C}$ for $10 \mathrm{~s}$, annealing at $60^{\circ} \mathrm{C}\left(62^{\circ} \mathrm{C}\right.$ for CCND2) for $20 \mathrm{~s}$, and extension at $72^{\circ} \mathrm{C}$ for $20 \mathrm{~s}$. A dilution series of $10^{2}, 10^{3}, 10^{4}, 10^{5}$, and $10^{6}$ copies of template DNA served as internal standard for quantification. Gene copy numbers were calculated based on standard curves using Opticon Monitor 2 Software (MJ Research, Inc.) and normalized to GAPDH. Data represent normalized fold-change +/- SEM.

\section{Western blot analysis}

Whole cell lysates were isolated by lysing cells with immunoprecipitation (IP) buffer (25 mM HEPES, pH 7.4; $150 \mathrm{mM} \mathrm{NaCl} ; 1 \mathrm{mM}$ EDTA; 0.5\% Triton X-100) followed by flash freeze/thaw treatment and centrifugation. Protein concentrations were determined by the Bradford assay (Bio-Rad Protein Assay, Bio-Rad, Hercules, CA). Proteins $(20-30 \mu \mathrm{g})$ were separated by SDS-PAGE on a 4$12 \%$ bis-Tris gel (NuPAGE Novex, Invitrogen, Carlsbad, CA) and transferred to nitrocellulose membranes (Invitrogen). Ponceau $\mathrm{S}$ red staining and $\beta$-actin protein levels were used as protein loading controls. Membranes were incubated in primary antibodies specific against DNMT1 (1:1000) (Santa Cruz Biotechnology, Inc., Santa Cruz, $\mathrm{CA}$ ) overnight at $4^{\circ} \mathrm{C}$. Secondary antibodies were conjugated with horseradish peroxidase (HRP) (Santa Cruz), and proteins were detected by Western Lightning Chemiluminescence Reagent Plus (PerkinElmer Life Sciences, Boston, MA) and imaged by Alpha Innotech photodocumentation system. Densitometry and quantifications were performed using NIH Image J software.

\section{Bisulfite modification}

Genomic DNA from cells was extracted using the DNeasy Blood and Tissue Kit (Qiagen, Valencia, CA). Genomic DNA $(0.5-1 \mu \mathrm{g})$ was treated with sodium bisulfite via the EZ DNA Methylation-Gold Kit (Zymo Research, Irvine, CA). Bisulfite treatments changed unmethylated cytosines into uracils while leaving methylated cytosines unmodified. Bisulfite-treated genomic DNA was used for further analysis of methylation status of CpG sites via methyl-specific PCR (MSP) and bisulfite DNA sequencing.

\section{Methyl-specific PCR (MSP)}

PCR amplification was performed on the bisulfite-treated DNA samples using primer sets targeting CpG-rich 
region in the cyclin D2 promoter. The MSP primer sequences were based on previous reports and primer binding positions were numbered from the transcriptional start site [25]: unmethylated reaction, 5'GTTATGTTATGTTTGTTGTATG -3' (sense, -1372 to -1350), and 5' - TAAAATCCACCAACACAATCA -3' (antisense, -1150 to -1170 ) and methylated reaction, 5'GTTACGTTATGTTCGTTGTACG -3' (sense, -1372 to -1350), and 5'- TAAAATCGCCGCCAACACGATCG -3' (antisense, -1150 to -1173). PCR was conducted using MSP buffer containing $16.6 \mathrm{mM}$ ammonium sulfate, 67 $\mathrm{mM}$ Tris (pH 8.8), $6.7 \mathrm{mM} \mathrm{MgCl}_{2}$, and $10 \mathrm{mM} \beta$-mercaptoethanol. Touchdown PCR condition was as follows: $95^{\circ} \mathrm{C}$ for $5 \mathrm{~min}$, followed by 10 cycles of $95^{\circ} \mathrm{C}$ for $30 \mathrm{~s}$, $62^{\circ} \mathrm{C}$ for $30 \mathrm{~s}, 72^{\circ} \mathrm{C}$ for $45 \mathrm{~s}$, and 30 cycles of $95^{\circ} \mathrm{C}$ for $30 \mathrm{~s}, 55^{\circ} \mathrm{C}$ for $30 \mathrm{~s}, 72^{\circ} \mathrm{C}$ for $45 \mathrm{~s}$, and a final extension step of $5 \mathrm{~min}$ at $72^{\circ} \mathrm{C}$. PCR products (223-bp) were analyzed on $3 \%$ low melt agarose gels and stained with ethidium bromide.

\section{Bisulfite DNA sequencing}

For bisulfite DNA sequencing analysis, genomic DNA was digested with AflIII restriction enzyme (New England Biolabs) and precipitated in the presence of GenElute LPA (Sigma-Aldrich, St. Louis, MO) prior to sodium bisulfite treatment. PCR primers were designed to amplify a CpG-rich region spanning from -1700 to $-1250 \mathrm{bp}$ from the transcription start site, which contains 24 CpG sites. Bisulfite primer sequences were: 5'AGCTATTGGCTATGCAAATAGAGGG-3' (-1670 to -1645, forward) and 5'- CCCTTTAATATATTTCACTCCAA-3' (-1261 to -1284 , reverse). PCR conditions described in the preceding section were used for amplification. Following PCR amplification, gel-purified bands were cloned into the pCR2.1 vector using the TOPO TA Cloning Kit (Invitrogen). Multiple clones (minimum of ten) from each PCR product were submitted for DNA sequencing at the Center for Genome Research \& Biocomputing Core Laboratories (Oregon State University, Corvallis, OR). Transcription Element Search Software (TESS) accessed through the World Wide Web was used to identify transcription factor binding sites within the cyclin D2 promoter region.

\section{Global Methylation Status}

Global methylation status of LnCap after treatments was assessed by using the MethylFlash ${ }^{\mathrm{TM}}$ Methylated DNA Quantification Kit (Epigentek, Brooklyn, NY) according to manufacturer's protocols with $200 \mathrm{ng}$ of genomic DNA.

\section{Statistics}

Data from independent triplicate $(\mathrm{n}=3)$ experiments were collected and statistical significance between SFN- treated and other treatments were determined by oneway ANOVA and Tukey-Krammer Multiple Comparison test using GraphPad Prism V5.0 software (GraphPad, San Diego, CA). A P value of $<0.05$ was considered statistically significant.

\section{Results \\ Sulforaphane decreased DNA methyltransferase expression}

We assessed the effects of SFN on the expressions of DNMTs (DNMT1, DNMT3a, and DNMT3b) in benign hyperplasia (BPH-1), LnCap and PC3 prostate cancer cells. Cells were treated with SFN $(15 \mu \mathrm{M}$ and $30 \mu \mathrm{M})$, and assayed for DNMT1, $3 a$ and $3 b$ transcript levels after 48 h. DNMT1 protein expression was also examined by western blot in treated cells. In BPH-1 and PC3 cells, SFN at both treatment doses significantly decreased DNMT1 and $3 a$ mRNA expression, but did not significantly change $D N M T 1$ protein expression (Figure 1). In LnCap cells, SFN significantly decreased DNMT1 and $3 b$ mRNA expressions, and DNMT1 protein expression (Figure 1). Previous study indicated that concentrations around $10 \mu \mathrm{M}$ SFN effectively inhibited HDAC activity in colonic mucosa in vivo, and one would consume about 1 cup (106 g) of broccoli sprouts per day to achieve similar plasma levels in humans [27]. This shows that the lowest treatment concentration in this study $(15 \mu \mathrm{M})$ that decreased DNMT expressions was within practical limits. 5-Aza-dC did not significantly affect DNMTs expression, indicating that 5-Aza$\mathrm{dC}$ inhibits DNMT enzymatic activity rather than expression, consistent with the mechanism by which 5Aza-dC inhibits DNMT through direct binding [28]. Alternatively, global inhibition of DNA methylation by 5-Aza-dC treatments may result in AP-1 dependent induction of DNMT1 expression similarly to observation in mouse embryonal cell line, P19 [29]. SFN appeared to most significantly suppress transcript and protein levels of DNMTs in LnCap cells. Previous studies also demonstrated that over-expression of cyclin D2 induced antiproliferative effects on LnCap cells, but not PC3 cells [30]. Therefore, LnCap cells were used to study subsequent endpoints.

\section{Sulforaphane decreased global DNA methylation and Cyclin D2 promoter methylation}

DNA methylation plays an important role in regulating cyclin D2 expression ([20-23,25,26,31]. To explore the effects of SFN on DNA methylation, we first examined the effects of SFN treatment on the global methylation status of LnCap cells, followed by detailed investigation of the methylation status of cyclin D2 promoter region via methyl-specific PCR (MSP) and bisulfite sequencing analysis. SFN $(30 \mu \mathrm{M})$ and 5-Aza-dC significantly 

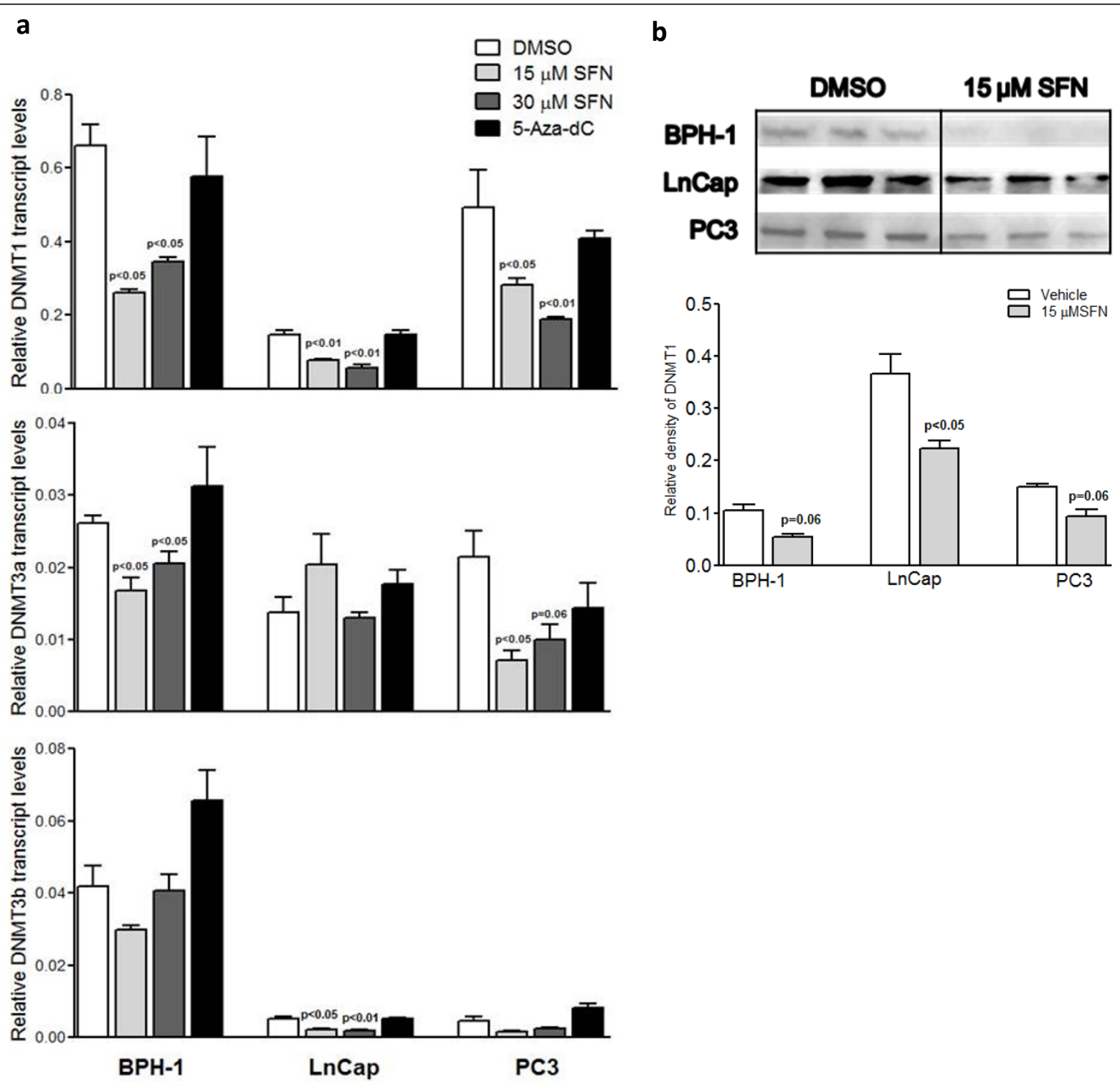

Figure 1 SFN decreased mRNA and protein expressions of DNA methyltransferases in prostate cancer cells. a. Benign hyperplasia cells (BPH-1), LnCap and PC3 cells were treated with SFN (15 and $30 \mu \mathrm{M})$ or 5-Aza-dC (5 $\mu \mathrm{M})$ for $48 \mathrm{~h}$. RNA was extracted and cDNA synthesized for qRT-PCR. Values are fold change of gene copy numbers normalized to GAPDH and compared to vehicle. $\mathbf{b}$. Whole cell lysates were extracted and DNMT1 protein levels were analyzed by western blot. The lower graph represents the relative density of DNMT1 normalized to $\beta$-actin levels. Results represent means $\pm \mathrm{SEM}, \mathrm{n}=3$. P values represent treatment values compared to vehicle.

decreased global methylation in LnCap cells after $24 \mathrm{~h}$ treatments (Figure 2), suggesting systematic de-methylating effects by SFN.

To specifically investigate the promoter methylation status of cyclin D2, an initial screen for cyclin D2 promoter methylation was performed by MSP, followed by verification via bisulfite sequence analysis. MSP screening suggested that there was a trend of decreasing methylation associated with increasing SFN treatment (Figure 3). Treatment with de-methylating agent, 5-Aza-
$\mathrm{dC}$, significantly increased un-methylated product compared to control. Since MSP is limited to provide semiquantitative analysis of a few CpG sites; we verified the MSP findings with bisulfite sequencing. To study the extent of promoter methylation, the CpG-rich region of the cyclin D2 promoter further upstream spanning nucleotides -1700 to -1250 bp (a total of 24 CpG sites) was sequenced after bisulfite modification of genomic DNA from cells treated with SFN for $48 \mathrm{~h}$. As shown in Figure 4, the CpG island examined was partially 


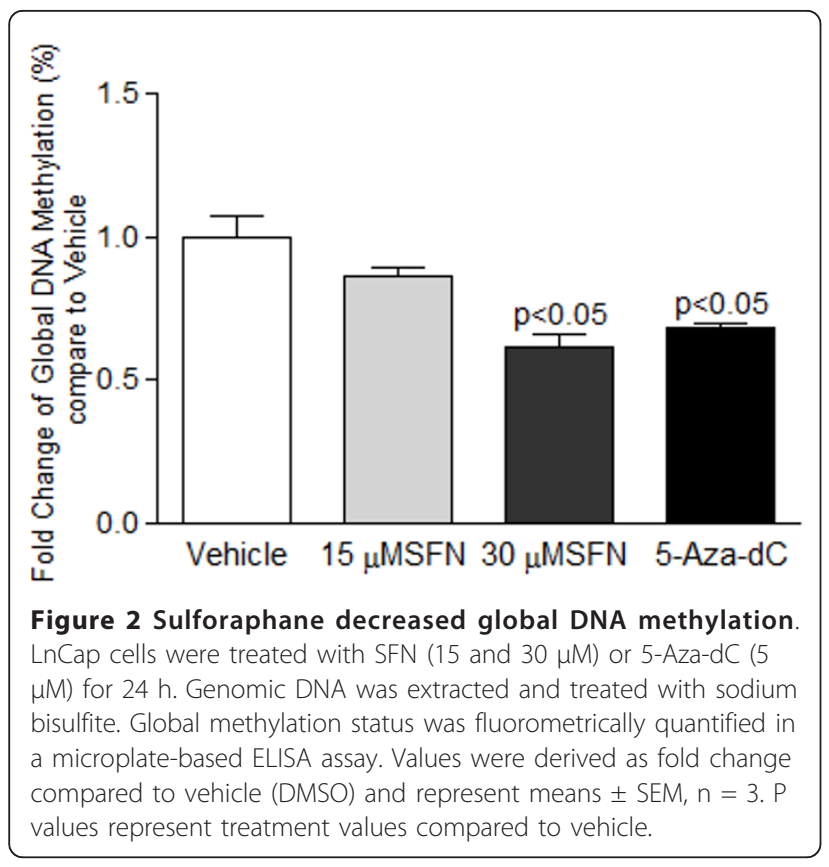

methylated in LnCap cells in the vehicle control group. 5-Aza-dC treatment produced a trend toward decreased methylation, and SFN-treatment resulted in a significant decrease in methylated $\mathrm{CpG}$ sites in this region. In particular, the c-Myc transcription factor binding site at CpG residue 23 and 24 were hyper-methylated in

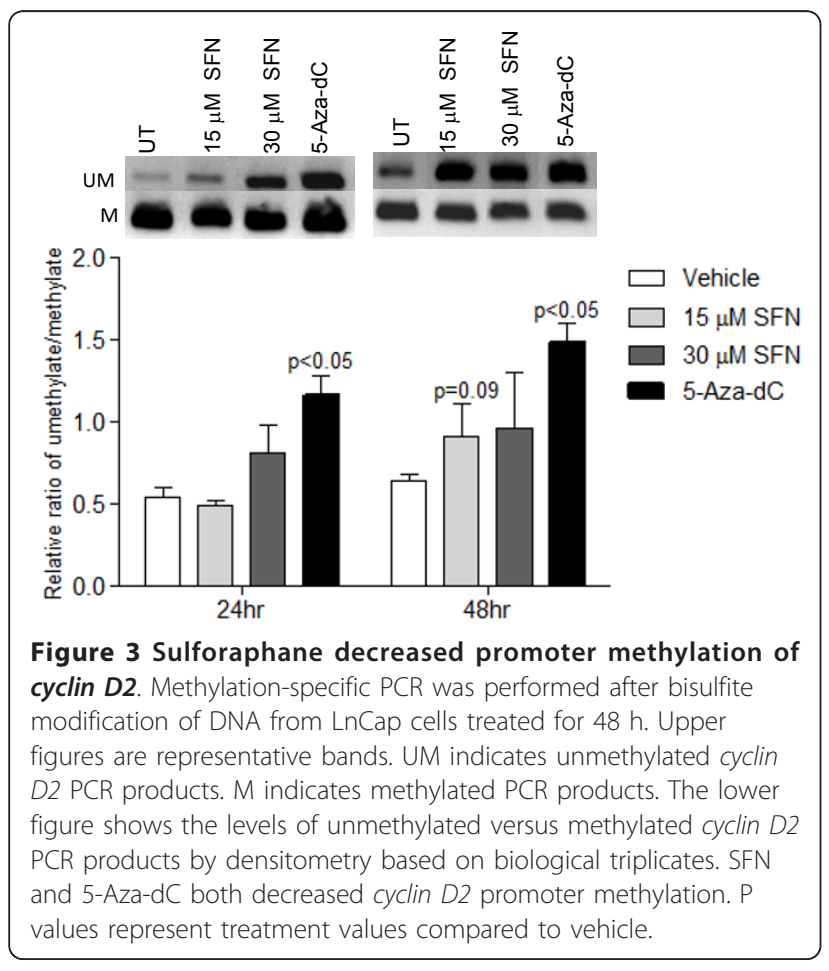

vehicle control, and SFN treatment significantly decreased methylation at these CpG sites ( $\mathrm{p}<0.05)$.

Sulforaphane induced cyclin D2 expression in LnCap Cells Previous reports stated that promoter methylation of cyclin D2 was associated with transcriptional silencing in gastric cancer cell lines [25]. By using qRT-PCR, cyclin D2 mRNA expression was determined in prostate cancer cells treated with SFN. At $24 \mathrm{~h}, \mathrm{SFN}$ dose-dependently increased cyclin D2 mRNA expression (Figure 5). There were no significant changes in cyclin D2 mRNA levels associated with 5 -Aza-dC treatment (data not shown), possibly due to shorter treatment time compared to previous reports. Previous studies showed that the ability of 5-Aza-dC to enhance expression of cyclin D2 was more marked if gastric cancer cells were treated for at least 5 days [25].

\section{Discussion}

Epigenetic silencing through promoter hypermethylation and histone deacetylation is responsible for transcriptional repression of numerous tumor suppressor genes and growth regulatory genes in cancer cells [32-34]. A tightly regulated balance exists in normal cells among these processes, but disruption of this balance contributes to carcinogenesis. Recent studies have suggested novel chemo-preventative properties of SFN as an HDAC and DNMT inhibitor [15,35]. SFN was shown to have anti-proliferative and pro-apoptotic effects in many cancer cells, including prostate cancer [35-37]. However, the molecular mechanisms by which SFN regulates various genes that govern these processes remain to be elucidated. The current study demonstrates that SFN also impacts global DNA methylation and site-specific demethylation of the cyclin D2 promoter. These results suggest that the ability of SFN to alter DNA methylation of specific tumor suppressor genes may be an important mechanism leading to prostate chemoprevention.

Previous studies indicate that cyclin D2 promoter methylation is more extensive in malignant than nonmalignant human prostate tissue [31] and treatment with 5-Aza-dC and TSA increased cyclin D2 expression in prostate cancer cell lines [30]. In the same study, over-expression of cyclin D2 induced anti-proliferative effects on LnCap cells, but not PC3 cells, suggesting that the inhibitory effects of cyclin D2 is limited to ARdependent prostate cancer cells [30]. Similar to previous reports, our study showed that LnCap cells had lower expression of cyclin D2 compared to BPH-1 cells, a non- tumorigenic cell line (data not shown). Previous studies have implicated that SFN is an HDAC inhibitor. In prostate cancer cells, such as LnCap and PC3 cells, SFN treatment significantly inhibits HDAC activity $[35,38]$. Combined with findings from these studies, 


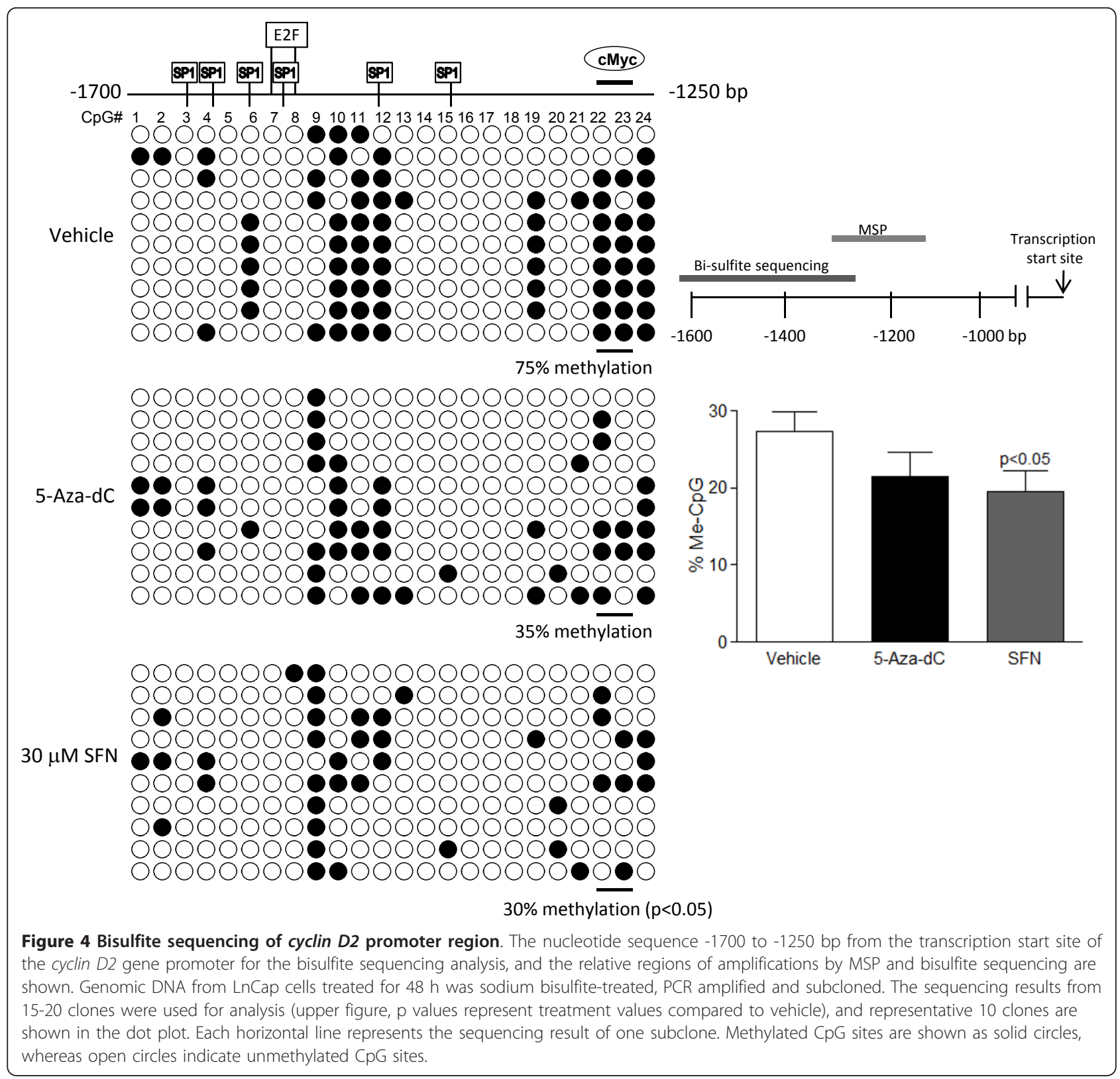

SFN's anti-proliferative effects may be mediated, at least in part, through de-methylation of the cyclin D2 promoter and restoration of cyclin D2 expression. It is possible that SFN-mediated both HDAC and DNMT inhibition and collectively allows chromatin remodeling for access of various transcription factors and de-suppression of the cyclin $D 2$ promoter.

To identify potential DNA methylation changes mediated by SFN, we examined the global methylation status and the methylation status of $\mathrm{CpG}$ islands in the cyclin D2 promoter region (-1700 to -1250) in LnCap cells. The methylation analysis indicated that 5 -Aza-dC induced more systemic de-methylation by significantly decreasing global methylation, whereas SFN showed more pronounced de-methylating effects in the cyclin D2 promoter region. More specifically, there was a significant decrease in methylation at the transcription factor c-Myc binding region. C-Myc has been implicated in modulating gene expression through epigenetic modifications. Classically, c-Myc's repressive effects on gene expression are attributed to inhibition of $\mathrm{Sp} 1$ transcriptional activity [39], and cyclin D2 is directly induced by c-Myc [40]. More recently, it was suggested that c-Myc modulates DNMT activity through direct binding or indirectly through an interaction with Mitz-1 to repress transcriptional activity, such as observed with the p21 


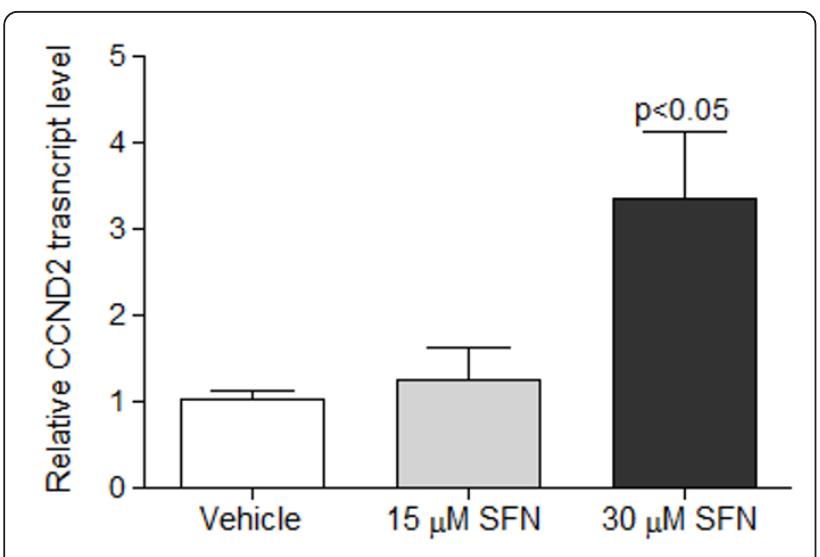

Figure 5 Sulforaphane increased transcript levels of cyclin D2. LnCap cells were treated with SFN (15 and $30 \mu \mathrm{M})$ for $24 \mathrm{~h}$. RNA was extracted and CDNA synthesized for qRT-PCR. SFN increased transcript levels of cyclin D2 compared with vehicle (DMSO). Values are fold change of gene copy numbers normalized to GAPDH and compared to vehicle, and represent means $\pm S E M, n=3$. $P$ values represent treatment values compared to vehicle.

promoter $[39,41,42]$. Furthermore, the core consensus sequence of c-Myc DNA binding site (CACGTG) contains a CpG site which is frequently methylated in vivo. Methylation of the consensus site blocks Myc/Max binding and trans-activation, but whether this influences the dynamics of Myc/Max heterodimer interactions with chromosomes remains to be elucidated [43]. It is important to recognize that global de-methylation has also been linked to increase genomic instability, and future studies are crucial to investigate whether such effects are advantageous for chemo-prevention using de-methylating compounds such as SFN. Furthermore, it is unclear how SFN treatment leads to selective de-methylation of specific CpG sites, but SFN may indirectly affect regulations of DNMTs and their specificities toward certain CpG sites. Nevertheless, SFN's effect on de-methylating the c-Myc binding site suggests that restoration of transcriptional expression of cyclin D2 may be dependent on $\mathrm{c}-\mathrm{Myc}$ trans-activation. Future experiments utilizing chromatin immunoprecipitation (ChIP) will be essential to elucidate the detailed interactions and the role of c-Myc binding. Furthermore, it is possible that other regions may demonstrate more pronounced differential methylation pattern with SFN treatment. The analysis of other regions on the promoter and their impact on cyclin D2 re-expression is an important area for future research. Moreover, the higher treatment concentration $(30 \mu \mathrm{M})$ in this study that altered methylation pattern in the cyclin D2 promoter (Figure 4) was a somewhat high concentration compared to SFN derived from dietary sources. However, it is possible that longer exposure of SFN at lower dosages could achieve the same outcomes. The findings here provide a proof of concept of the effects of SFN on DNA methylation, but the precise dosing regimens and treatment timing to obtain optimal effects are important areas of research.

Consistent with previous findings that SFN decreased expression of DNMT1 and DNMT3a in breast cancer cells [15], SFN also decreased DNMTs expressions in our study. We found that DNMT1 and $3 a$ mRNA expressions were significantly decreased by SFN in BPH-1 and PC3 cells, but only a trend of decrease in $D N M T 1$ protein expression. In contrast, we found that DNMT1 and $3 b$ were down-regulated with SFN treatment in LnCap cells, but not DNMT3a. These results suggest that the responses to SFN treatment are specific to cell types. SFN may act as a dual epigenetic regulator by inhibiting both HDACs and DNMTs, leading to altered gene expression and contribute to anti-proliferative effects. It has been well established that DNA methylation and histone modifications cross-talk and cooperate in the regulation of gene transcription. Recent in vitro studies have shown that DNMT1 interacts physically with HDAC1 or 2. DNMTs recruit class 1 HDACs to function as co-repressors in the transcription of tumor suppressor genes [44-46]. Jones et al. demonstrated that trichostatin A (TSA), a HDAC inhibitor, relieves transcriptional repression at methylated $\mathrm{CpG}$ islands, and implicated that DNA methylation provided the nucleosomal infrastructure for HDAC-dependent chromatin modification and transcriptional silencing $[34,47]$. The SFN-mediated inhibition of DNMT expressions may be an important contributing factor in facilitating de-methylation of cyclin D2 promoter observed in this study. In addition to transcriptional regulation of DNMTs, it is also possible that alternative post-transcriptional and post-translational regulations of DNMTs are targeted by SFN. SFN may modulate histone profile and DNMT pathways at the same time. Previous studies from our lab established that SFN ( $\geq 15 \mu \mathrm{M})$ significantly decreased HDAC activity and expressions in LnCap cells $[38,48]$. SFN also potently increased p21 expressions. DNMT1 has been shown to competitively bind to proliferating nuclear cell antigen (PCNA) at the same site as p21, a tumor suppressor that inhibits DNA replication [49]. In ovarian cancer cells, SFN inhibits degradation of retinoblastoma protein ( $\mathrm{Rb})$, which directly binds to DNMT1, sequesters its activity and disrupts formation of DNMT-DNA complexes [46,50]. It is very likely that SFN regulates DNMT indirectly through HDACs or other protein interactions. Further examination of the direct coordination between these epigenetic marks is an exciting area for future studies. Studies that identify specific methyl binding proteins, transcriptional activators or repressors and chromatin remodeling will be essential to decipher the exact mechanism of cyclin 
$D 2$ promoter regulation by SFN. Furthermore, SFN also decreased telomerase reverse transcriptase ( $h T E R T)$ expression through promoter de-methylation and epigenetic modulations in breast cancer cells, suggesting that SFN may target other hypermethylated gene promoters that are dys-regulated during carcinogenesis and warrant further investigation. Overall, we demonstrated the SFN induced up-regulation of cyclin D2 in prostate cancer cells, and examined SFN as an epigenetic modulator by altering methylation status in the cyclin $D 2$ promoter region. These findings provide additional insights into the mechanisms by which SFN may act as a diet-derived epigenetic modulator of gene expression and agent for prostate cancer prevention.

\section{Acknowledgements}

This work was supported by NIH grants CA090890, Oregon AES (OR00735), the Environmental Health Science Center at Oregon State University (NIEHS P30 ES00210). We acknowledge support from Dr. Rong Wong for technical assistance with qRT-PCR.

\section{Author details}

'School of Biological and Population Health Sciences, 103 Milam Hall, Oregon State University, Corvallis, OR 97331, USA. 'Linus Pauling Institute, 571 Weniger Hall, Oregon State University, Corvallis, OR 97331, USA. ${ }^{3}$ Department of Environmental \& Molecular Toxicology, 1007 Ag Life Sciences Building, Oregon State University, Corvallis, OR 97331, USA.

\section{Authors' contributions}

$\mathrm{AH}$ performed the experiments including QRT-PCR for DNMTs and Cyclin D2, the global methylation analysis, bisulfite sequencing, and data and statistical analysis. YZ performed the immunoblot analysis on DNMTs, and CW performed the MSP. AH, RD, DW and EH conceived and participated in design and coordination of the study. $\mathrm{AH}$ and $\mathrm{EH}$ drafted the manuscript. All authors read and approved the final manuscript.

\section{Competing interests}

The authors declare that they have no competing interests.

Received: 19 April 2011 Accepted: 26 October 2011

Published: 26 October 2011

\section{References}

1. Ambrosini GL, de Klerk NH, Fritschi L, Mackerras D, Musk B: Fruit, vegetable, vitamin $\mathrm{A}$ intakes, and prostate cancer risk. Prostate Cancer Prostatic Dis 2008, 11:61-66.

2. Giovannucci E, Rimm EB, Liu Y, Stampfer MJ, Willett WC: A prospective study of cruciferous vegetables and prostate cancer. Cancer Epidemiol Biomarkers Prev 2003, 12:1403-1409.

3. Joseph MA, Moysich KB, Freudenheim JL, Shields PG, Bowman ED, Zhang Y, Marshall JR, Ambrosone CB: Cruciferous vegetables, genetic polymorphisms in glutathione S-transferases $\mathrm{M} 1$ and $\mathrm{T} 1$, and prostate cancer risk. Nutr Cancer 2004, 50:206-213.

4. Kristal AR, Lampe JW: Brassica vegetables and prostate cancer risk: a review of the epidemiological evidence. Nutr Cancer 2002, 42:1-9.

5. Steinbrecher A, Nimptsch K, Husing A, Rohrmann S, Linseisen J: Dietary glucosinolate intake and risk of prostate cancer in the EPIC-Heidelberg cohort study. Int I Cancer 2009, 125:2179-2186.

6. Chiao JW, Chung FL, Kancherla R, Ahmed T, Mittelman A, Conaway CC: Sulforaphane and its metabolite mediate growth arrest and apoptosis in human prostate cancer cells. Int J Oncol 2002, 20:631-636.

7. Patra SK, Patra A, Dahiya R: Histone deacetylase and DNA methyltransferase in human prostate cancer. Biochem Biophys Res Commun 2001, 287:705-713.
8. Singh AV, Xiao D, Lew KL, Dhir R, Singh SV: Sulforaphane induces caspasemediated apoptosis in cultured PC-3 human prostate cancer cells and retards growth of PC-3 xenografts in vivo. Carcinogenesis 2004, 25:83-90.

9. Singh SV, Herman-Antosiewicz A, Singh AV, Lew KL, Srivastava SK, Kamath R, Brown KD, Zhang L, Baskaran R: Sulforaphane-induced G2/M phase cell cycle arrest involves checkpoint kinase 2-mediated phosphorylation of cell division cycle 25C. J Biol Chem 2004, 279:25813-25822.

10. Wang L, Liu D, Ahmed T, Chung FL, Conaway C, Chiao JW: Targeting cell cycle machinery as a molecular mechanism of sulforaphane in prostate cancer prevention. Int J Oncol 2004, 24:187-192.

11. Bhamre S, Sahoo D, Tibshirani R, Dill DL, Brooks JD: Temporal changes in gene expression induced by sulforaphane in human prostate cancer cells. Prostate 2009, 69:181-190.

12. Dashwood RH, Ho E: Dietary agents as histone deacetylase inhibitors: sulforaphane and structurally related isothiocyanates. Nutr Rev 2008, 66(Suppl 1):S36-38.

13. Telang $U$, Brazeau DA, Morris ME: Comparison of the effects of phenethyl isothiocyanate and sulforaphane on gene expression in breast cancer and normal mammary epithelial cells. Exp Biol Med 2009, 234:287-295.

14. Traka M, Gasper AV, Smith JA, Hawkey CJ, Bao Y, Mithen RF: Transcriptome analysis of human colon Caco-2 cells exposed to sulforaphane. J Nutr 2005, 135:1865-1872

15. Meeran SM, Patel SN, Tollefsbol TO: Sulforaphane causes epigenetic repression of hTERT expression in human breast cancer cell lines. PLOS One 5 :e11457.

16. Zhang P: The cell cycle and development: redundant roles of cell cycle regulators. Curr Opin Cell Biol 1999, 11:655-662.

17. Takano Y, Kato Y, Masuda M, Ohshima Y, Okayasu I: Cyclin D2, but not cyclin D1, overexpression closely correlates with gastric cancer progression and prognosis. J Pathol 1999, 189:194-200.

18. Takano Y, Kato Y, van Diest PJ, Masuda M, Mitomi H, Okayasu I: Cyclin D2 overexpression and lack of p27 correlate positively and cyclin E inversely with a poor prognosis in gastric cancer cases. Am J Pathol 2000, 156:585-594.

19. Mermelshtein A, Gerson A, Walfisch S, Delgado B, Shechter-Maor G, Delgado J, Fich A, Gheber L: Expression of D-type cyclins in colon cancer and in cell lines from colon carcinomas. Br J Cancer 2005, 93:338-345.

20. Dhillon VS, Shahid M, Husain SA: CpG methylation of the FHIT, FANCF, cyclin-D2, BRCA2 and RUNX3 genes in Granulosa cell tumors (GCTs) of ovarian origin. Mol Cancer 2004, 3:33.

21. Buckley MF, Sweeney KJ, Hamilton JA, Sini RL, Manning DL, Nicholson RI, deFazio A, Watts CK, Musgrove EA, Sutherland RL: Expression and amplification of cyclin genes in human breast cancer. Oncogene 1993, 8:2127-2133

22. Fackler MJ, McVeigh M, Evron E, Garrett E, Mehrotra J, Polyak K, Sukumar S, Argani P: DNA methylation of RASSF1A, HIN-1, RAR-beta, Cyclin D2 and Twist in in situ and invasive lobular breast carcinoma. Int $J$ Cancer 2003, 107:970-975

23. Virmani A, Rathi A, Heda S, Sugio K, Lewis C, Tonk V, Takahashi T, Roth JA, Minna JD, Euhus DM, Gazdar AF: Aberrant methylation of the cyclin D2 promoter in primary small cell, nonsmall cell lung and breast cancers. Int J Cancer 2003, 107:341-345.

24. Matsubayashi H, Sato N, Fukushima N, Yeo CJ, Walter KM, Brune K, Sahin F, Hruban RH, Goggins M: Methylation of cyclin D2 is observed frequently in pancreatic cancer but is also an age-related phenomenon in gastrointestinal tissues. Clin Cancer Res 2003, 9:1446-1452.

25. Yu J, Leung WK, Ebert MP, Leong RW, Tse PC, Chan MW, Bai AH, To KF, Malfertheiner P, Sung JJ: Absence of cyclin D2 expression is associated with promoter hypermethylation in gastric cancer. $\mathrm{Br} J$ Cancer 2003, 88:1560-1565.

26. Henrique R, Costa VL, Cerveira N, Carvalho AL, Hoque MO, Ribeiro FR, Oliveira J, Teixeira MR, Sidransky D, Jeronimo C: Hypermethylation of Cyclin D2 is associated with loss of mRNA expression and tumor development in prostate cancer. J Mol Med 2006, 84:911-918.

27. Myzak MC, Dashwood WM, Orner GA, Ho E, Dashwood RH: Sulforaphane inhibits histone deacetylase in vivo and suppresses tumorigenesis in Apc-minus mice. Faseb J 2006, 20:506-508.

28. Patel K, Dickson J, Din S, Macleod K, Jodrell D, Ramsahoye B: Targeting of 5-aza-2'-deoxycytidine residues by chromatin-associated DNMT1 induces 
proteasomal degradation of the free enzyme. Nucleic Acids Res 2010, 38:4313-4324.

29. Slack A, Cervoni N, Pinard M, Szyf M: Feedback regulation of DNA methyltransferase gene expression by methylation. Eur J Biochem 1999, 264:191-199.

30. Kobayashi T, Nakamura E, Shimizu Y, Terada N, Maeno A, Kobori G, Kamba T, Kamoto T, Ogawa O, Inoue T: Restoration of cyclin D2 has an inhibitory potential on the proliferation of LNCaP cells. Biochem Biophys Res Commun 2009, 387:196-201.

31. Padar A, Sathyanarayana UG, Suzuki M, Maruyama R, Hsieh JT, Frenkel EP, Minna JD, Gazdar AF: Inactivation of cyclin D2 gene in prostate cancers by aberrant promoter methylation. Clin Cancer Res 2003, 9:4730-4734.

32. Baylin SB, Herman JG: DNA hypermethylation in tumorigenesis: epigenetics joins genetics. Trends Genet 2000, 16:168-174.

33. Brooks AR, Shiffman D, Chan CS, Brooks EE, Milner PG: Functional analysis of the human cyclin D2 and cyclin D3 promoters. J Biol Chem 1996 271:9090-9099.

34. Jones PA, Baylin SB: The fundamental role of epigenetic events in cancer. Nat Rev Genet 2002, 3:415-428.

35. Ho E, Clarke JD, Dashwood RH: Dietary sulforaphane, a histone deacetylase inhibitor for cancer prevention. J Nutr 2009, 139:2393-2396.

36. Chu WF, Wu DM, Liu W, Wu L, Li DZ, Xu DY, Wang XF: Sulforaphane induces G2-M arrest and apoptosis in high metastasis cell line of salivary gland adenoid cystic carcinoma. Oral Oncol 2009, 45:998-1004.

37. Pledgie-Tracy A, Sobolewski MD, Davidson NE: Sulforaphane induces cell type-specific apoptosis in human breast cancer cell lines. Mol Cancer Ther 2007, 6:1013-1021.

38. Clarke JD, Hsu A, Yu Z, Dashwood RH, Ho E: Differential effects of sulforaphane on histone deacetylases, cell cycle arrest and apoptosis in normal prostate cells versus hyperplastic and cancerous prostate cells. Mol Nutr Food Res 2011, 55:999-1009.

39. Gartel AL, Ye X, Goufman E, Shianov P, Hay N, Najmabadi F, Tyner AL: Myc represses the p21(WAF1/CIP1) promoter and interacts with Sp1/Sp3. Proc Natl Acad Sci USA 2001, 98:4510-4515.

40. Bouchard C, Thieke K, Maier A, Saffrich R, Hanley-Hyde J, Ansorge W, Reed S, Sicinski P, Bartek J, Eilers M: Direct induction of cyclin D2 by Myc contributes to cell cycle progression and sequestration of p27. Embo J 1999, 18:5321-5333.

41. Brenner C, Deplus R, Didelot C, Loriot A, Vire E, De Smet C, Gutierrez A, Danovi D, Bernard D, Boon T, et al: Myc represses transcription through recruitment of DNA methyltransferase corepressor. Embo J 2005, 24:336-346.

42. Gartel AL: A new mode of transcriptional repression by c-myc: methylation. Oncogene 2006, 25:1989-1990.

43. Cole MD, McMahon SB: The Myc oncoprotein: a critical evaluation of transactivation and target gene regulation. Oncogene 1999, 18:2916-2924.

44. Chiam K, Tilley WD, Butler LM, Bianco-Miotto T: The dynamic and static modification of the epigenome by hormones: a role in the developmental origin of hormone related cancers. Biochim Biophys Acta 2009, 1795:104-109.

45. Lo PK, Sukumar S: Epigenomics and breast cancer. Pharmacogenomics 2008, 9:1879-1902.

46. Robertson KD, Ait-Si-Ali S, Yokochi T, Wade PA, Jones PL, Wolffe AP: DNMT1 forms a complex with $\mathrm{Rb}, \mathrm{E} 2 \mathrm{~F} 1$ and $\mathrm{HDAC} 1$ and represses transcription from E2F-responsive promoters. Nat Genet 2000, 25:338-342.

47. Widschwendter M, Jones PA: DNA methylation and breast carcinogenesis. Oncogene 2002, 21:5462-5482.

48. Myzak MC, Hardin K, Wang R, Dashwood RH, Ho E: Sulforaphane inhibits histone deacetylase activity in $\mathrm{BPH}-1, \mathrm{LnCaP}$ and $\mathrm{PC}-3$ prostate epithelial cells. Carcinogenesis 2006, 27:811-819.

49. Chuang LS, lan HI, Koh TW, Ng HH, Xu G, Li BF: Human DNA-(cytosine-5) methyltransferase-PCNA complex as a target for p21WAF1. Science 1997, 277:1996-2000.

50. Razin A, Webb C, Szyf M, Yisraeli J, Rosenthal A, Naveh-Many T, SciakyGallili N, Cedar H: Variations in DNA methylation during mouse cell differentiation in vivo and in vitro. Proc Natl Acad Sci USA 1984, $81: 2275-2279$

doi:10.1186/1868-7083-3-3

Cite this article as: Hsu et al:: Promoter de-methylation of cyclin D2 by sulforaphane in prostate cancer cells. Clinical Epigenetics 2011 3:3.

\section{Submit your next manuscript to BioMed Central and take full advantage of:}

- Convenient online submission

- Thorough peer review

- No space constraints or color figure charges

- Immediate publication on acceptance

- Inclusion in PubMed, CAS, Scopus and Google Scholar

- Research which is freely available for redistribution 